\title{
From GWAS to the clinic: risk factors for intracranial aneurysms
}

Ynte M Ruigrok and Gabriel JE Rinkel*

\begin{abstract}
Subarachnoid hemorrhage (SAH) from a ruptured intracranial aneurysm is a devastating subset of stroke, occurring in relatively young people (mean age around 50 years) of whom around a third die within the initial weeks after the bleed. Environmental and genetic risk factors both have a role in SAH. A recent genomewide association study of intracranial aneurysms in Finnish, Dutch and Japanese cohorts totaling 5,891 cases and 14,181 controls identified three new loci strongly associated with intracranial aneurysms on chromosomes 18q11.2 and 10q24.32, and replicated two previously found loci on chromosomes 8q11.23-q12.1 and 9p21.3. However, these five intracranial aneurysm risk loci identified so far explain only up to $5 \%$ of the familial risk of intracranial aneurysms, which makes genetic risk prediction tests currently unfeasible for intracranial aneurysms. New approaches, including identification of causal variants, rare variants and copy number variants, such as insertions and deletions, may improve genetic risk prediction for SAH and intracranial aneurysms. This may lead to diagnostic tools for identifying individuals at increased risk for aneurysm formation and rupture of aneurysms. In this way, genetic diagnostic tools will identify the people who will benefit most from screening by imaging studies for aneurysms and those who are most likely to benefit from preventive treatment of incidentally discovered aneurysms.
\end{abstract}

\section{Subarachnoid hemorrhage: epidemiology and socioeconomic burden}

Subarachnoid hemorrhage (SAH) from a ruptured intracranial aneurysm is a devastating subset of stroke. Intracranial aneurysms are mostly situated on the larger

*Correspondence: g.j.e.rinkel@umcutrecht.nl

Utrecht Stroke Center, University Medical Center Utrecht, 3508 GA Utrecht, The Netherlands arteries supplying the brain. These arteries run through the so-called subarachnoid space, which is the very small space between the brain and the skull. If such an aneurysm ruptures, a bleed under arterial pressure occurs in this subarachnoid space. Clinically, patients have a sudden, unusual severe headache, which is combined with a sudden loss of consciousness in half of them. The mean age at time of SAH is around 50 years, and the incidence is around 1 per 10,000 people per year, with highest rates in Japan and Finland and higher rates in women than in men [1]. Despite improvements in patient management and improved prognosis, around a third of patients still die in the initial months after the hemorrhage [2].

Because of the relatively young age of onset and its poor prognosis, the socioeconomic burden of SAH is considerable. The number of productive life years lost in the population from SAH is as large as that lost from ischemic stroke [3] and, according to a recent study, a total of 80,356 life years and 74,807 quality-adjusted life years were lost as a result of SAH in the UK in 2005 [4]. Further improvements in prognosis in SAH patients on a population level will be difficult to achieve, because one in eight patients dies immediately, before reaching the hospital [5]. Therefore, prevention seems an attractive option to reduce the burden of $\mathrm{SAH}$, and knowledge on risk factors is essential for the development of preventive measures.

\section{Risk factors for subarachnoid hemorrhage}

Risk factors for SAH can be divided into modifiable - or environmental - and non-modifiable risk factors. Established environmental risk factors for $\mathrm{SAH}$ are smoking, hypertension and excessive alcohol intake [6]. Nonmodifiable risk factors include a familial preponderance of $\mathrm{SAH}$, female gender and systemic diseases, such as polycystic kidney disease and the vascular type of Ehlers Danlos disease $[7,8]$. The familial preponderance suggests a genetic component in the risk for SAH. Although SAH is a rare disease, intracranial aneurysms are relatively common, with a prevalence of around 1 per 50 people [9]. It therefore seems relevant to discriminate risk factors for SAH into risk factors for the presence of an 
aneurysm and risk factors for rupture of aneurysms. For presence of aneurysms, atherosclerosis, a familial preponderance and polycystic kidney disease are the main risk factors. On the other hand, only the size and site of the aneurysm, age and gender have been consistently identified as risk factors for rupture of aneurysm. All in all, our knowledge of risk factors for both the development and rupture of intracranial aneurysms remains rather meager, and hopes are high that genetic research will further increase our understanding of such risk factors.

\section{Genetic factors for subarachnoid hemorrhage: insights from genome-wide association studies}

Because both environmental and genetic risk factors have a role in SAH and intracranial aneurysms, it is a so-called complex disease. For the identification of the genetic factors responsible for a complex disease, candidate gene studies were initially used. These studies are hypothesisbased and genes are selected on the basis of their known function and the assumption that they are involved in the development of the disease (so-called functional candidate genes). The association between the disease and a specific allele of a single nucleotide polymorphism (SNP) within the functional candidate genes is analyzed between patients and controls. In intracranial aneurysms, most of these studies included relatively small numbers of patients and controls. Therefore, results have been conflicting or have not been replicated. These studies have been reviewed elsewhere [10-12].

A disadvantage of the hypothesis-based approach of candidate gene studies is that genes involved in the pathogenesis of a disease through unknown pathways are overlooked. The hypothesis-free approach by genomewide association studies (GWASs) allow researchers to overcome this drawback because in these studies nearly all common variation in the entire genome can be tested for association with a disease [13,14]. In the past few years, GWASs have identified hundreds of genetic loci contributing to common complex diseases [13,14]. In a GWAS the genome is analyzed for common variability associated with the risk of disease by genotyping approximately 500,000 SNPs in several thousand cases and control participants. These genetic loci include common, low-risk variants (those that are present in more than $5 \%$ of the population) that confer a small risk of disease, typically with odds ratios (ORs) of 1.2 to 1.5 $[13,15]$. However, the variants identified so far by GWAS in relation to complex disease explain only a small proportion of the genetic risk for those conditions $[16,17]$. For example, the 18 loci associated with type 2 diabetes explain only about $6 \%$ of its heritability [18], and the 32 loci associated with Crohn's disease account for $20 \%$ of its heritability [19]. Consequently, the use of genetic risk prediction and the subsequent opportunities for personalized medicine in complex disease are not yet possible [20].

The first GWAS of intracranial aneurysms included Finnish, Dutch and Japanese cohorts making up over 2,100 cases and 8,000 controls. Common SNPs on chromosomes 2q, 8q and 9p showed a significant association with intracranial aneurysm, with odds ratios of 1.24 to 1.36 [21]. In a follow-up GWAS, additional European case and control cohorts were included and the original Japanese replication cohort was increased, resulting in a cohort of 5,891 cases and 14,181 controls [22]. This follow-up study identified three new loci strongly associated with intracranial aneurysms on chromosomes 18q11.2 $\left(\mathrm{OR}=1.22, P=1.1 \times 10^{-12}\right)$, 13q13.1 $\left(\mathrm{OR}=1.20, P=2.5 \times 10^{-9}\right)$ and 10q24.32 $(\mathrm{OR}=$ 1.29, $\left.P=1.2 \times 10^{-9}\right)$. The previously discovered associations of $8 \mathrm{q} 11.23-\mathrm{q} 12.1\left(\mathrm{OR}=1.28, P=1.3 \times 10^{-12}\right)$ and $9 \mathrm{p} 21.3\left(\mathrm{OR}=1.31, P=1.5 \times 10^{-22}\right)$ were replicated [22]

The $8 \mathrm{q}$ locus contains a single gene, SOX17, which encodes a transcription factor that has a pivotal role in endothelial cell function [23].The strongest associated SNP within the 9p locus lies close to CDKN2A, which encodes the cyclin-dependent kinase inhibitor p16INK4a and the alternative open reading frame ARF, a regulator of p53 activity, and $C D K N 2 B$, which encodes the cyclindependent kinase inhibitor p15INK4b. In addition, a non-protein-coding gene (ANRIL) lies within this locus. A recently described mutant mouse with a deletion corresponding to the human $9 \mathrm{p} 21$ locus showed a marked suppression of the gene expression of $C D K N 2 B$ and CDKN2A [24]. Aortic smooth-muscle cells in culture from these mice showed increased proliferative activity compared with aortic smooth-muscle cells from wildtype mice [24].

The strongest associated SNP on the 10q locus is located within the CNNM2 gene, which encodes cyclin M2. Not much is known on its function. The 13q locus includes the gene START-domain-containing 13 (STARD13), of which overexpression leads to suppression in cell proliferation [25], and the gene KLOTHO (KL). $K L$-deficient mice show extensive and accelerated arteriosclerosis in association with medial calcification of the aorta and both medial calcification and intimal thickening of medium-sized muscular arteries [26]. Finally, the gene product of $R B B P 8$, located within the $18 \mathrm{q}$ locus, is one of the proteins that bind directly to retinoblastoma protein, which regulates cell proliferation [27]. An important common denominator of the gene products of the candidate genes in the five intracranial loci seems to be involvement in cell proliferation.

Assuming a fourfold increase in the risk of intracranial aneurysm among siblings of cases [28,29], the five intracranial aneurysm risk loci identified thus far only 
explain up to $5 \%$ of the familial risk of intracranial aneurysms [22]. From the results of these two GWASs we can conclude that, as for other complex diseases, the possible development of genetic risk prediction tests also remains currently unfeasible for intracranial aneurysms.

\section{Applications for diagnosis: the need for further research}

So far, the current GWAS findings explain only a small proportion of the heritability of complex diseases, including the disease SAH and intracranial aneurysms. Further research, including new approaches to detect rare variants using next generation sequencing [30] and structural variants, including copy number variants such as insertions and deletions [31], may improve genetic risk prediction for SAH and intracranial aneurysms. Knowledge of the genetic determinants for intracranial aneurysms may provide diagnostic tools for identifying individuals at increased risk for aneurysm formation; the identified individuals will benefit most from screening by imaging studies. Future studies should not only look for genetic determinants of intracranial aneurysms, but also investigate genetic determinants of rupture of aneurysms. Given that only a minority of all unruptured aneurysms do rupture, these genetic determinants may provide a powerful tool for identifying patients with unruptured aneurysms who are at high risk of rupture and who are therefore most likely to benefit from preventive treatment of the aneurysm [32].

\section{Abbreviations}

GWAS, genome-wide association study; SAH, subarachnoid hemorrhage; SNP, single nucleotide polymorphism.

\section{Competing interests}

The authors declare that they have no competing interests.

\section{Authors' contributions}

Both authors have contributed equally to this article.

Published: 10 September 2010

\section{References}

1. de Rooij NK, Linn FHH, van der Plas JA, Algra A, Rinkel GJE: Incidence of subarachnoid haemorrhage: a systematic review with emphasis on region, age, gender and time trends. J Neurol Neurosurg Psychiatry 2007, 78:1365-1372

2. Nieuwkamp DJ, Setz LE, Algra A, Linn FH, de Rooij NK, Rinkel GJE: Changes in case fatality of aneurysmal subarachnoid haemorrhage over time, according to age, sex, and region: a meta-analysis. Lancet Neurol 2009, 8:635-642.

3. Johnston SC, Selvin S, Gress DR: The burden, trends, and demographics of mortality from subarachnoid hemorrhage. Neurology 1998, 50:1413-1418.

4. Rivero-Arias O, Gray A, Wolstenholme J: Burden of disease and costs of aneurysmal subarachnoid haemorrhage (aSAH) in the United Kingdom. Cost EffResour Alloc 2010, 8:6.

5. Huang J, Van Gelder JM: The probability of sudden death from rupture of intracranial aneurysms: a meta-analysis. Neurosurgery 2002, 51:1101-1107.

6. Feigin VL, Rinkel GJE, Lawes CM, Algra A, Bennett DA, van Gijn J, Anderson CS: Risk factors for subarachnoid hemorrhage. an updated systematic review of epidemiological studies. Stroke 2005, 36:2773-2780.

7. Gieteling EW, Rinkel GJE: Characteristics of intracranial aneurysms and subarachnoid haemorrhage in patients with polycystic kidney disease. J Neurol 2003, 250:418-423.

8. Pepin MG, Schwarze U, Superti-Furga A, Byers PH: Clinical and genetic features of Ehlers-Danlos syndrome type IV, the vascular type. N Engl J Med 2000, 342:673-680

9. Rinkel GJE, Djibuti M, Algra A, van Gijn J: Prevalence and risk of rupture of intracranial aneurysms: a systematic review. Stroke 1998, 29:251-256.

10. Ruigrok YM, Rinkel GJE: Genetics of intracranial aneurysms. Stroke 2008, 39:1049-1055.

11. Krischek B, Inoue I: The genetics of intracranial aneurysms. J Hum Genet 2006, 51:587-594.

12. Nahed BV, Bydon M, Ozturk AK, Bilguvar K, Bayrakli F, Gunel M: Genetics of intracranial aneurysms. Neurosurgery 2007, 60:213-225.

13. Hindorff LA, Sethupathy P, Junkins HA, Ramos EM, Mehta JP, Collins FS, Manolio TA: Potential etiologic and functional implications of genomewide association loci for human diseases and traits. Proc Natl Acad Sci USA 2009, 106:9362-9367.

14. A Catalog of Published Genome-Wide Association Studies [http://www. genome.gov/26525384]

15. Pritchard JK: Are rare variants responsible for susceptibility to complex diseases? Am J Hum Genet 2001, 69:124-137.

16. Maher B: Personal genomes: the case of the missing heritability. Nature 2008, 456:18-21.

17. Manolio TA, Brooks LD, Collins FS: A HapMap harvest of insights into the genetics of common disease. J Clin Invest 2008, 118:1590-1605.

18. Zeggini E, Scott L, Saxena R, Voight BF, Marchini JL, Hu T, de Bakker PI, Abecasis GR, Almgren P, Andersen G, Ardlie K, Boström KB, Bergman RN, Bonnycastle LL, Borch-Johnsen K, Burtt NP, Chen H, Chines PS, Daly MJ, Deodhar P, Ding CJ, Doney AS, Duren WL, Elliott KS, Erdos MR, Frayling TM, Freathy RM, Gianniny L, Grallert H, Grarup N, et al:: Meta-analysis of genomewide association data and large-scale replication identifies additional susceptibility loci for type 2 diabetes. Nat Genet 2008, 40:638-645.

19. Barrett JC, Hansoul S, Nicolae DL, Cho JH, Duerr RH, Rioux JD, Brant SR, Silverberg MS, Taylor KD, Barmada MM, Bitton A, Dassopoulos T, Datta LW, Green T, Griffiths AM, Kistner EO, Murtha MT, Regueiro MD, Rotter Jl, Schumm LP, Steinhart AH, Targan SR, Xavier RJ; NIDDK IBD Genetics Consortium, Libioulle C, Sandor C, Lathrop M, Belaiche J, Dewit O, Gut I, et al:: Genomewide association defines more than 30 distinct susceptibility loci for Crohn's disease. Nat Genet 2008, 40:955-962.

20. Wray NR, Goddard ME, Visscher PM: Prediction of individual genetic risk of complex disease. Curr Opin Genet Dev 2008, 18:257-263.

21. Bilguvar K, Yasuno K, Niemelä M, Ruigrok YM, von Und Zu Fraunberg M, van Duijn CM, van den Berg LH, Mane S, Mason CE, Choi M, Gaál E, Bayri Y, Kolb L, Arlier Z, Ravuri S, Ronkainen A, Tajima A, Laakso A, Hata A, Kasuya H, Koivisto T, Rinne J, Ohman J, Breteler MM, Wijmenga C, State MW, Rinkel GJE, Hernesniemi J, Jääskeläinen JE, Palotie A, et al: Susceptibility loci for intracranial aneurysm in European and Japanese populations. Nat Genet 2008, 40:1472-1477.

22. Yasuno K, Bilguvar K, Bijlenga P, Low SK, Krischek B, Auburger G, Simon M, Krex D, Arlier Z, Nayak N, Ruigrok YM, Niemelä M, Tajima A, von und zu Fraunberg M, Dóczi T, Wirjatijasa F, Hata A, Blasco J, Oszvald A, Kasuya H, Zilani G, Schoch B, Singh P, Stüer C, Risselada R, Beck J, Sola T, Ricciardi F, Aromaa A, Illig T, et al:: Genome-wide association study of intracranial aneurysm identifies three new risk loci. Nat Genet 2010, 42:420-425.

23. Francois M, Koopman P, Beltrame M: SoxF genes: key players in the development of the cardio-vascular system. Int J Biochem Cell Biol 2010, 42:445-448.

24. Visel A, Zhu Y, May D, Afzal V, Gong E, Attanasio C, Blow MJ, Cohen JC, Rubin EM, Pennacchio LA: Targeted deletion of the 9p21 non-coding coronary artery disease risk interval in mice. Nature 2010, 464:409-412.

25. Leung TH, Ching YP, Yam JW, Wong CM, Yau TO, Jin DY, Ng IO: Deleted in liver cancer 2 (DLC2) suppresses cell transformation by means of inhibition of RhoA activity. Proc Natl Acad Sci USA 2005, 102:15207-15212.

26. Kuro-o M, Matsumura Y, Aizawa H, Kawaguchi H, Suga T, Utsugi T, Ohyama Y, Kurabayashi M, Kaname T, Kume E, Iwasaki H, lida A, Shiraki-lida T, Nishikawa S, Nagai R, Nabeshima Yl: Mutation of the mouse klotho gene leads to a syndrome resembling ageing. Nature 1997, 390:45-51.

27. Nevins JR: Toward an understanding of the functional complexity of the E2F and retinoblastoma families. Cell Growth Differ 1998, 9:585-593.

28. Schievink Wl: Genetics of intracranial aneurysms. Neurosurgery 1997, 40:651-663. 
29. Cannon Albright LA, Camp NJ, Farnham JM, MacDonald J, Abtin K, Rowe KG A genealogical assessment of heritable predisposition to aneurysms. J Neurosurg 2003, 99:637-643.

30. Cirulli ET, Goldstein DB: Uncovering the roles of rare variants in common disease through whole-genome sequencing. Nat Rev Genet 2010, 11:415-425.

31. McCarthy Ml, Hirschhorn JN: Genome-wide association studies: potential next steps on a genetic journey. Hum Mol Genet 2008, 17:R156-R165.
32. Wermer MJ, van der Schaaf IC, Algra A, Rinkel GJE: Risk of rupture of unruptured intracranial aneurysms in relation to patient and aneurysm characteristics: an updated meta-analysis. Stroke 2007, 38:1404-1410.

doi:10.1186/gm182

Cite this article as: Ruigrok YM, Rinkel GJE: From GWAS to the clinic: risk factors for intracranial aneurysms. Genome Medicine 2010, 2:61. 